\title{
Relationship between inflammatory markers and mild cognitive impairment in Chinese patients with type 2 diabetes: a case-control study
}

Miaoyan Zheng ${ }^{1}$, Baocheng Chang ${ }^{1}$, Liqiang Tian², Chunyan Shan ${ }^{1}$, Hui Chen ${ }^{3}$, Yuxia Gao ${ }^{4}$, Guowei Huang ${ }^{5,6,7}$ and Meilin Zhang $5,6,7^{*}$

\begin{abstract}
Background: Several studies have indicated that inflammatory markers were associated with the risk of mild cognitive impairment (MCl) in type 2 diabetes (T2D). Serum folate was related to $\mathrm{MCl}$ as well as inflammation. However, no studies have investigated the association between inflammatory markers and $\mathrm{MCl}$ taking account of serum folate level in T2D patients. This study aimed to conduct a case-control study to evaluate the association between inflammatory markers and $\mathrm{MCl}$ taking account of serum folate level in Chinese patients with T2D.

Methods: This study consisted of 126 T2D patients ( 63 cases with MCl and 63 controls without MCI). Clinical parameters, serum folate, high-sensitivity C-reactive protein (hs-CRP), interleukin-6 (IL-6), tumor necrosis factor-a (TNF-a) were measured. Spearman correlation analysis and logistic regression analysis were used to analyze the association between the inflammatory markers and the risk of $\mathrm{MCl}$ in T2D patients.

Results: There were higher serum hs-CRP, IL-6 and TNF-a in T2D cases with MCl compared with the controls. Serum folate was negatively correlated with hs-CRP, TNF-a, and IL- $6(P<0.05)$. In multivariate analysis, there were significant associations between serum IL-6 or hs-CRP and $\mathrm{MCl}$ after adjusting for the confounding variables, however, the association between hs-CRP and $\mathrm{MCl}$ disappeared after further adjusting for serum folate. Further subgroup analysis revealed that the significant association between hs-CRP and $\mathrm{MCl}$ only existed in the low folate subgroup $(<7.0 \mathrm{\mu g} / \mathrm{L}$; $\mathrm{OR}=3.34,95 \% \mathrm{Cl}: 1.05-10.64)$, not in the high folate subgroup ( $\geq 7.0 \mu \mathrm{g} / \mathrm{L} ; \mathrm{OR}=2.16,95 \% \mathrm{Cl}$ : 0.68-6.88) after adjusting for the confounding variables.
\end{abstract}

Conclusions: Serum IL-6 and hs-CRP were associated with the risk of MCl in Chinese patients with T2D. Serum folate might modify the association between serum hs-CRP and MCl in T2D patients.

Keywords: Type 2 diabetes, Mild cognitive impairment, Inflammation, Folate, High-sensitivity C-reactive protein

\section{Background}

Alzheimer disease (AD) as well as type 2 diabetes (T2D) is age-related diseases and the incidences of the two diseases are increasing at an alarming rate. Mild cognitive impairment $(\mathrm{MCI})$ is characterized by an isolated memory deficit and a largely intact general cognitive functioning [1]. On

\footnotetext{
* Correspondence: zhangmeilin@tmu.edu.cn

${ }^{5}$ Department of Nutrition and Food Science, School of Public Health, Tianjin Medical University, Tianjin, China

${ }^{6}$ Tianjin Key Laboratory of Environment, Nutrition and Public Health, Tianjin, China

Full list of author information is available at the end of the article
}

the continuum of cognitive function, $\mathrm{MCI}$ represents a transitional state between and overlaps normal aging and $\mathrm{AD}$, and it is now recognized as a risk factor for $\mathrm{AD}$ [2]. There have been several prospective studies reported that T2D was one of risk factors for dementia and MCI, and the relative risk of $\mathrm{T} 2 \mathrm{D}$ to $\mathrm{AD}$ was approximately twice that of non-diabetics $[3,4]$. Animal study [5] and human studies $[6,7]$ have found that diabetes could accelerate the appearance of cerebrovascular inflammation and $A \beta$ deposition, as evidenced by increased levels of proinflammatory cytokines such as interleukin (IL-6) and tumor

(c) The Author(s). 2019 Open Access This article is distributed under the terms of the Creative Commons Attribution 4.0 International License (http://creativecommons.org/licenses/by/4.0/), which permits unrestricted use, distribution, and 
necrosis factor (TNF- $\alpha$ ). Furthermore, it has been demonstrated that adequate folate might help to delay or prevention of dementia and higher folate intake might decrease the risk of $\mathrm{AD}$ [8]. Recent studies have shown that the serum folate was related to lower concentrations of inflammatory markers and folate intake might help to control the inflammation process [9].

In previous, one cohort study of 168 Chinese elderly patients has demonstrated that plasma high-sensitivity C-reactive protein (hs-CRP) level was associated with cognitive function and development of dementia in nondiabetics [10]. Currently, several epidemiological studies have focus on the association between inflammatory markers and the risk of $\mathrm{MCI}$ in T2D patients [11, 12], which showed that hs-CRP or IL-6 were found to be associated with the risk of MCI among T2D patients. Moreover, it has been reported that MCI was often associated with folate [8] and folic acid supplementation appeared to improve cognitive function and reduce blood levels of $A \beta$-related biomarkers in MCI [13]. To our knowledge, no studies have investigated the association between inflammatory markers and $\mathrm{MCI}$ taking account of serum folate level in Chinese patients with T2D. Here, we conducted this case-control study to examine the relationship between inflammatory factors and MCI in Chinese patients with T2D.

\section{Methods \\ Subjects}

A case-control study was conducted at the Metabolic Disease Hospital of Tianjin Medical University from June 2016 to January 2017. The enrollment process was described in Fig. 1. Three hundred thirty-six elderly diabetic patients who were hospitalized for diabetes or its complications were enrolled. All the diabetic patients were met current international diagnostic standards for diabetes [14] and were treated with anti-diabetic medications, including oral hypoglycemic agents (OHAs) and/ or insulin injection on the basis of lifestyle interventions. Subjects with hypertension were treated with antihypertensive therapy. Subjects with dyslipidemia were treated with statins, except for those with fasting serum triglyceride were treated with fibrates to prevent acute pancreatitis. Subjects were excluded from the study if they

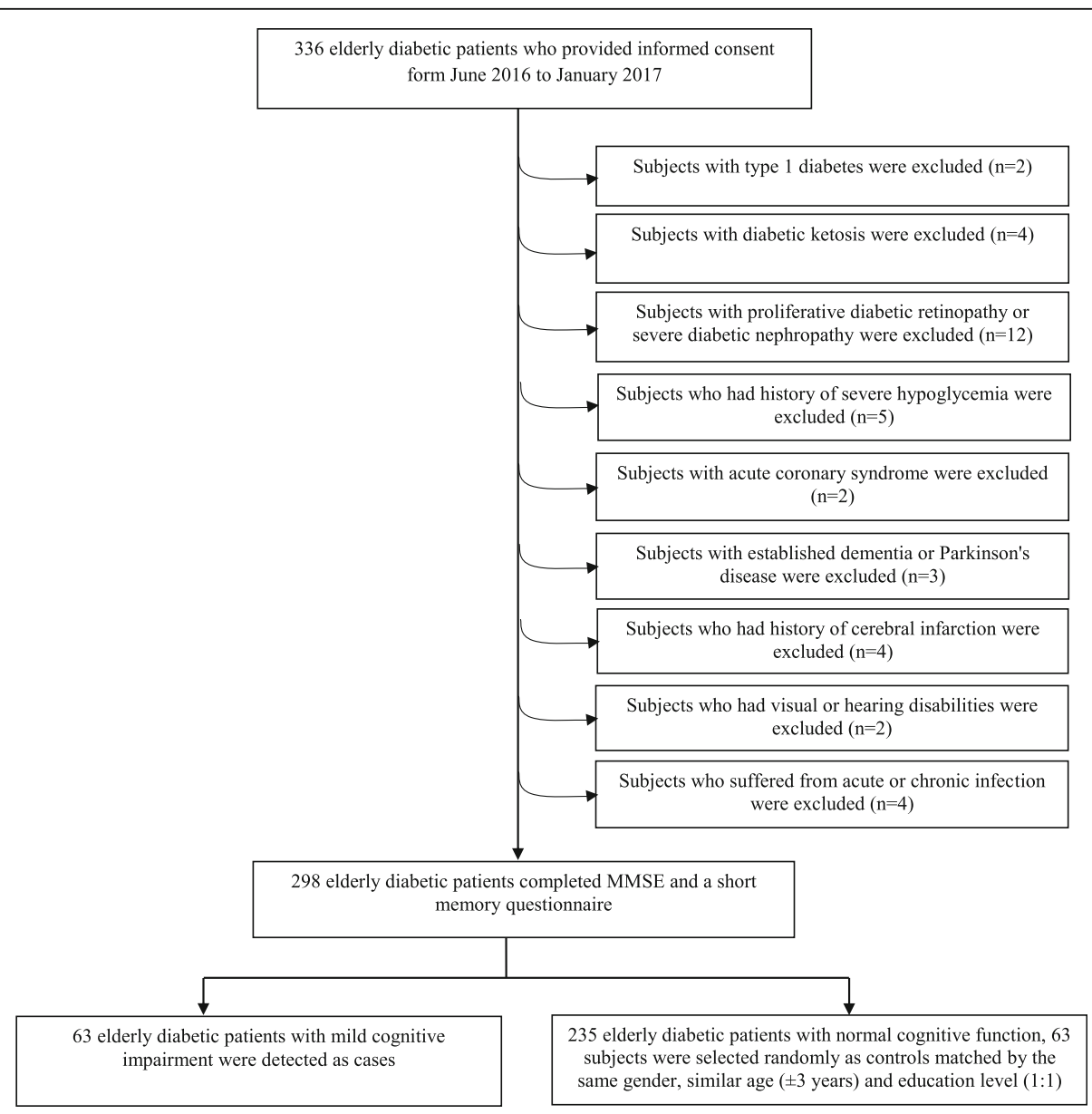

Fig. 1 Flow chart of the sample selection process. MMSE: Mini-Mental State Examination 
exhibited: (1) type 1 diabetes, (2) acute or severe chronic diabetic complications, such as diabetes ketosis, (3) proliferative diabetic retinopathy, diabetic foot infection or ulcer, (4) severe diabetic nephropathy: estimated glomerular filtration rate $(\mathrm{eGFR})<45 \mathrm{ml} / \mathrm{min} \cdot 1.73 \mathrm{~m}^{2}$; or urinary albumin creatinine ratio $>300 \mathrm{mg} / \mathrm{g}$; or eGFR $45-60 \mathrm{ml} / \mathrm{min}$ • $1.73 \mathrm{~m}^{2}$ and urinary albumin creatinine ratio $30-300 \mathrm{mg} / \mathrm{g}$ [15]. The eGFR was estimated by the Chronic Kidney Disease Epidemiology Collaboration creatinine equation [16], (5) history of severe hypoglycemia or hypoglycemia unawareness which the individuals required the assistance of another person to administer treatment [17], (6) acute coronary syndrome or other severe cardiovascular diseases, (7) neurological disorders, such as established dementia, Parkinson's disease and seizures, (8) any apparent past history of a cerebrovascular events, or presence of any clinically significant abnormality in brain computed tomography or magnetic resonance imaging scan, (9) visual or hearing disabilities; psychiatric disorder, (10) acute or chronic infection, or taking NSAIDS, antibiotics or steroids within the 3 months. Altogether, 39 subjects were excluded according the above exclusion criteria. Totally 298 T2D patients completed Mini-Mental State Examination (MMSE) [18] and a short memory questionnaire [19]. Sixty-three T2D patients with MCI were detected as cases. Accordingly, among the 235 diabetic subjects with normal cognitive function (NCF), 63 T2D ones were selected randomly as controls matched by same gender, similar age ( \pm 3 years) and education using an on-line Random Number Generator/Picker according to the visiting orders of subjects. Consequently, the final sample was composed of 63 cases and 63 controls (Fig. 1).

All subjects underwent MMSE [18] and a short memory questionnaire [19] by trained interviewers. The questionnaire aimed to distinguish if the patients complained about decreased subjective memory. The MMSE is a widely used brief cognitive screening test, which assesses space/time orientation, verbal memory, language, attention/calculation, and visuoconstructive abilities. Another questionnaire was used to determine whether the subjects had any impairment in activities of daily living (ADL) [20]. The patients who met the Petersen's diagnostic criteria [21] were defined as having MCI: subjective memory complaint and the evidence of objective memory impairment; the MMSE scores were above 13 , but $\leq 18$ or $\leq 20$ or $\leq 24$, with zero, or 1 to 6 years, or more than 6 years education, respectively; intact or minimal damage of ADL; but failure to meet the DSM-IIIR criteria of dementia [22]. The participants with NCF were defined as the subjects who had no subjective memory complaint or objective memory damage, and MMSE scores over the above values based on the corresponding education level.

The study protocol was approved by the Ethics Committee of Tianjin Medical University. Written informed consent was received from each patient.

\section{Data collection}

Height was measured without shoes to the nearest $1 \mathrm{~cm}$ and weight measured in light clothing to the nearest $0.1 \mathrm{~kg}$ on a beam balance scale. Body mass index (BMI) was calculated as weight in kilograms divided by the square of the height in meters $\left(\mathrm{kg} / \mathrm{m}^{2}\right)$. Blood pressure was measured twice on the left arm with subjects in a seated position after $15 \mathrm{~min}$ rest. These measures were averaged to get a mean blood pressure. Information about demographic characteristics, medication history, duration of diabetes, anti-diabetic medications (including OHAs and/or insulin) and diabetic complications, as well as lifestyle habits (smoking, drinking and physical activity) were collected by trained interviewers. Venous blood samples were taken from all participants after an overnight fast (12 $\mathrm{h}$ at least) and the samples were stored at $-80^{\circ} \mathrm{C}$ until assessment assayed performed. The glycated hemoglobin A1c (GHbA1c) was measured using high-performance liquid chromatography method. The levels of lipid profile including total cholesterol (TC), triglycerides (TG), high-density lipoprotein cholesterol (HDLC), low-density lipoprotein cholesterol (LDL-C) and fasting plasma glucose (FPG) were measured enzymatically on a Modular Analytics P800 analyzer (Roche Diagnostics, Indianapolis, IN).

\section{Measurement of serum folate and inflammation markers}

Blood samples $(2 \mathrm{~mL})$ were collected into anticoagulantfree tubes and centrifuged at $1000 \times g$ for $15 \mathrm{~min}$. Serum folate was determined by chemiluminescent assay (Access Immuno Systems, Beckman Coulter, Brea, CA). Serum hs-CRP was determined by immunologic turbidimetry (Orion Diagnostic, Espoo, Finland). Serum levels of TNF- $\alpha$ and IL- 6 were measured in duplicate using a commercially available enzyme-linked immunosorbent assay kit (Human IL-6 and Quantikine HS TNF- $\alpha$, Boster Biological Technology, Wuhan, China).

\section{Statistical analysis}

Mean and standard deviations (SD) or median (inter-quartile range) were used as descriptive statistics for continuous variables and percentages for categorical variables. For continuous variables, the paired-sample $t$ test or Wilcoxon rank-sum test was used for between-group comparisons, and chi-square test for categorical variables. Spearman correlation analysis was conducted to analyze the correlation between serum folate and inflammatory markers. Logistic regression analysis was used to assess the association between the inflammatory markers and risk of MCI. Odds ratio (OR) and corresponding 95\% confidence intervals (CI) were calculated. Model 1 was used to calculate the crude OR, and model 2 was adjusted for factors related diabetes including duration of diabetes (per year), HbA1c $(<7.0 \% / \geq 7.0 \%)$, anti-diabetic medications (only OHAs /only insulin/insulin plus OHAs), diabetic retinopathy 
(yes/no) and diabetic nephropathy (yes/no), and common cardiovascular diseases risk factors including smoking status (yes $/$ no), body mass index $\left(<24.0 \mathrm{~kg} / \mathrm{m}^{2} / 24.0-28.0 \mathrm{~kg} /\right.$ $\mathrm{m}^{2} / \geq 28.0 \mathrm{~kg} / \mathrm{m}^{2}$ ), hypertension (yes $/ \mathrm{no}$ ), LDL-C $(<2.6$ $\mathrm{mmol} / \mathrm{L} / \geq 2.6 \mathrm{mmol} / \mathrm{L}$ ). Model 3 was additional adjusted for serum folate. All statistical operations were performed using SPSS (version 13.0, Chicago, IL, USA). All reported $P$ values were two-sided and $P$ value less than 0.05 was considered to indicate a statistically significant difference.

\section{Results}

\section{Characteristics of study samples}

The socioeconomic data and MMSE scores of the subjects were shown in Table 1. Compared with the subjects in T2D-NCF group, those in T2D-MCI group had lower MMSE scores $(20.38 \pm 3.68$ vs. $26.75 \pm 2.84 ; P<0.001)$. The mean level of TC $(5.45 \pm 1.10 \mathrm{mmol} / \mathrm{L})$ in T2D-MCI group was significantly higher than that in T2D-NCF group $(5.00 \pm 1.00 \mathrm{mmol} / \mathrm{L}, P<0.05)$. The percentage of diabetic retinopathy $(42.9 \%)$, diabetic nephropathy $(41.3 \%)$, LDL$\mathrm{C} \geq 2.60 \mathrm{mmol} / \mathrm{L}(84.1 \%)$ in T2D-MCI group were significantly higher than that in T2D-NCF group (19.0, 19.0 and $66.7 \%$, respectively; $P<0.05)$. There were no significant differences in BMI, systolic blood pressure (SBP), diastolic blood pressure (DBP), the duration of diabetes, triglycerides, HDL-C, FPG, GHbA1c, the percent of hypertension, ADL scores, smoking status and drinking status between T2D-MCI group and T2D-NCF group $(P>0.05)$. In addition, there were no significant differences in all the above indices between the low folate subgroup $(<7.0 \mu \mathrm{g} / \mathrm{L})$ and the high folate subgroup $(\geq 7.0 \mu \mathrm{g} / \mathrm{L})$ in $\mathrm{T} 2 \mathrm{D}-\mathrm{MCI}$ group or T2D-NCF group $(P>0.05)$ (Table 1$)$.

\section{Comparisions of serum folate and inflammatory markers according to cognitive status}

The median value of serum folate in T2D-MCI group was significantly lower than that in T2D-NCF group (T2DMCI: 6.25(5.30-7.94) $\mu \mathrm{g} / \mathrm{L}$ vs. T2D-NCF: 8.07(6.65-10.40) $\mu \mathrm{g} / \mathrm{L})(P<0.01)$ (Table 2). Compared with the T2D-NCF group, the median values of serum TNF- $\alpha$, IL- 6 and hsCRP were significantly higher than that in T2D-MCI group $(P<0.05)$ (Table 2$)$.

\section{The correlations between serum folate and inflammatory markers}

Spearman correlation analysis showed that the serum folate was negatively correlated with hs-CRP, TNF- $\alpha$, and IL-6 ( $r$ value: $-0.33,-0.19,-0.21$, respectively; $P<0.05$ ) (Table 3 ).

\section{Odds ratios of $\mathrm{MCl}$ for inflammatory markers}

Table 4 showed the odds ratios of MCI across tertiles of inflammatory markers. In univariate analysis, compared with the subjects in the lowest tertile, those in the upper tertile of IL-6 (OR = 3.09, 95\%CI: 1.57-6.10; $P<0.05)$ and hs-CRP
$(\mathrm{OR}=2.25,95 \% \mathrm{CI}: 1.14-4.44 ; P<0.05)$ were associated with higher odds of MCI. The TNF- $\alpha$ was not associated with risk of MCI $(P>0.05)$. In multivariate analysis, the significant associations persisted after adjusted for the confounding variables including smoking, overweigh and obesity, duration of diabetes, anti-diabetic medications, HbA1c, hypertension, LDL-C, diabetic retinopathy and diabetic nephropathy. The significant association between IL- 6 and MCI persisted after further adjusting for serum folate, whereas the association between hs-CRP and MCI disappeared. Since the greatest reduction in neural tube defects has been observed at serum concentrations $\geq 7.0 \mu \mathrm{g} / \mathrm{L}$ [23], we further divided all the subjects into two subgroups according to the level of serum folate $(<7.0 \mu \mathrm{g} / \mathrm{L} / \geq 7.0 \mu \mathrm{g} / \mathrm{L})$ and evaluated the associations between hs-CRP and MCI among the two subgroups (Table 5). The significant association between hs-CRP and MCI only existed in the low folate subgroup $(<7.0 \mu \mathrm{g} / \mathrm{L})$ after adjusted for the above confounding factors $(\mathrm{OR}=3.34,95 \% \mathrm{CI}$ : $1.05-10.64)$, not in the high folate subgroup $(\geq 7.0 \mu \mathrm{g} / \mathrm{L} ; \mathrm{OR}=2.16,95 \% \mathrm{CI}$ : $0.68-6.88)$.

\section{Discussion}

Since AD and MCI is age-related disease and male sex as well as less education is significantly associated with cognitive decline in stroke-free patients, and some inflammatory markers such as TNF- $\alpha$ and IL-6 levels increase with increasing age in humans [24], we randomly selected the cases and controls matched by the same gender, similar age $( \pm 3$ years $)$ and education level. Several related factors of diabetes and its major complications, as well as cardiovascular diseases risk factors were correlated with inflammation [25-27] or cognition [3], we have excluded the patients who suffered cerebrovascular events or acute coronary syndrome. Intensive hypoglycemic therapy has been proposed to reduce the risk of diabetic complications. However, the insulin or sulfonylureas might increase the risk of severe hypoglycaemia, which was associated with an increased risk of cognitive dysfunction or dementia [28]. Thus, the subjects with history of severe hypoglycemia due to overdose of insulin or sulfonylureas were also excluded. The major finding of this study was that the T2D patients with MCI had higher plasma hs-CRP, IL-6 and TNF- $\alpha$ compared with the T2D patients with normal cognition. There was significant association between serum IL-6 or hs-CRP and MCI after adjusting for common confounding factors, however, the association between hs-CRP and MCI disappeared after further adjusting for serum folate.

Numerous studies have indicated the association of inflammation markers with increased risks for dementia, $\mathrm{MCI}$, and cognitive decline [6, 29, 30]. Zuliani G et al. have demonstrated that high levels of IL- $1 \beta$ and TNF- $\alpha$, but not IL-6, were associated with increased likelihood of having late-onset AD [31]. Similarly, Tarkowski et al. 


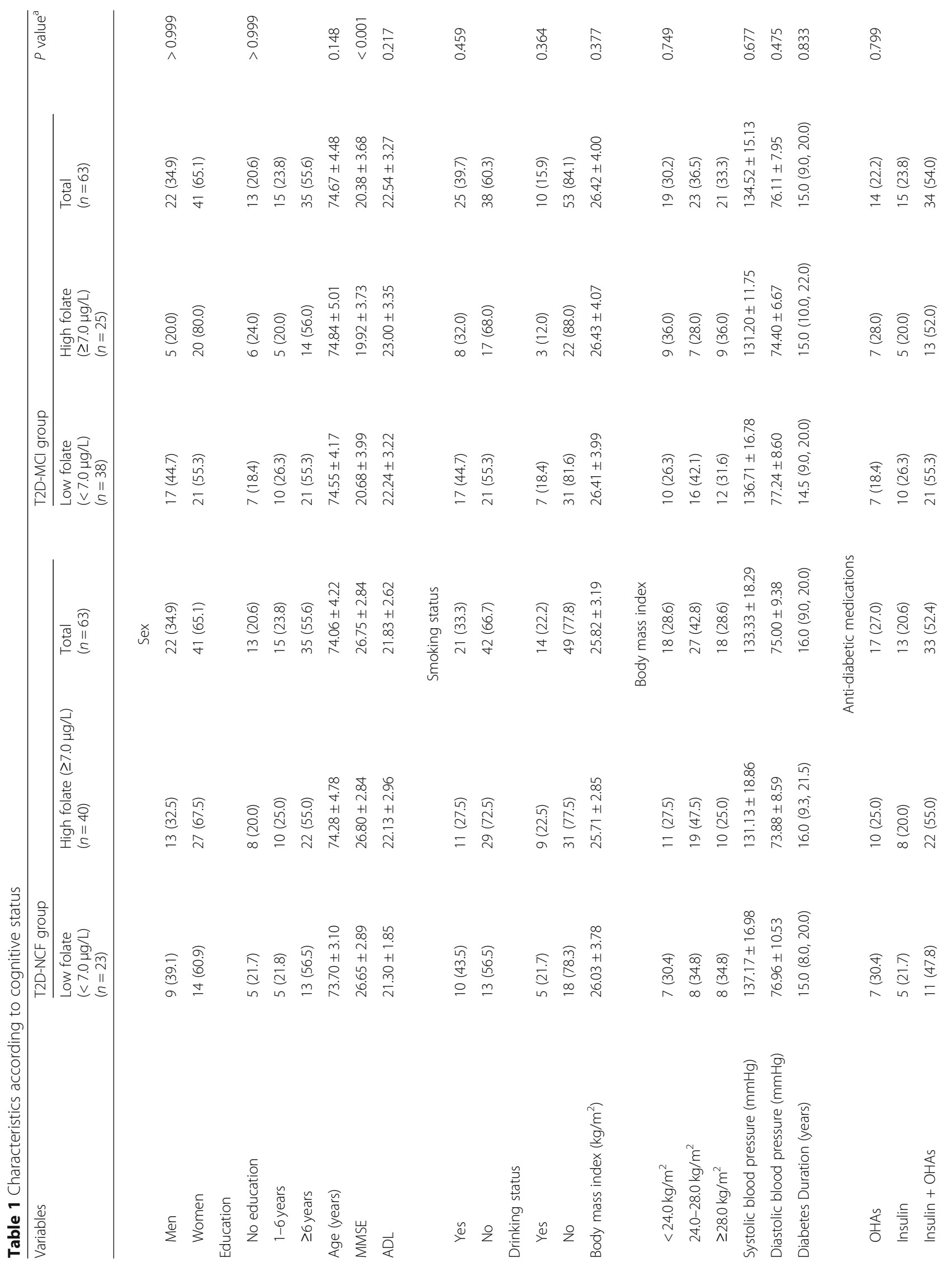




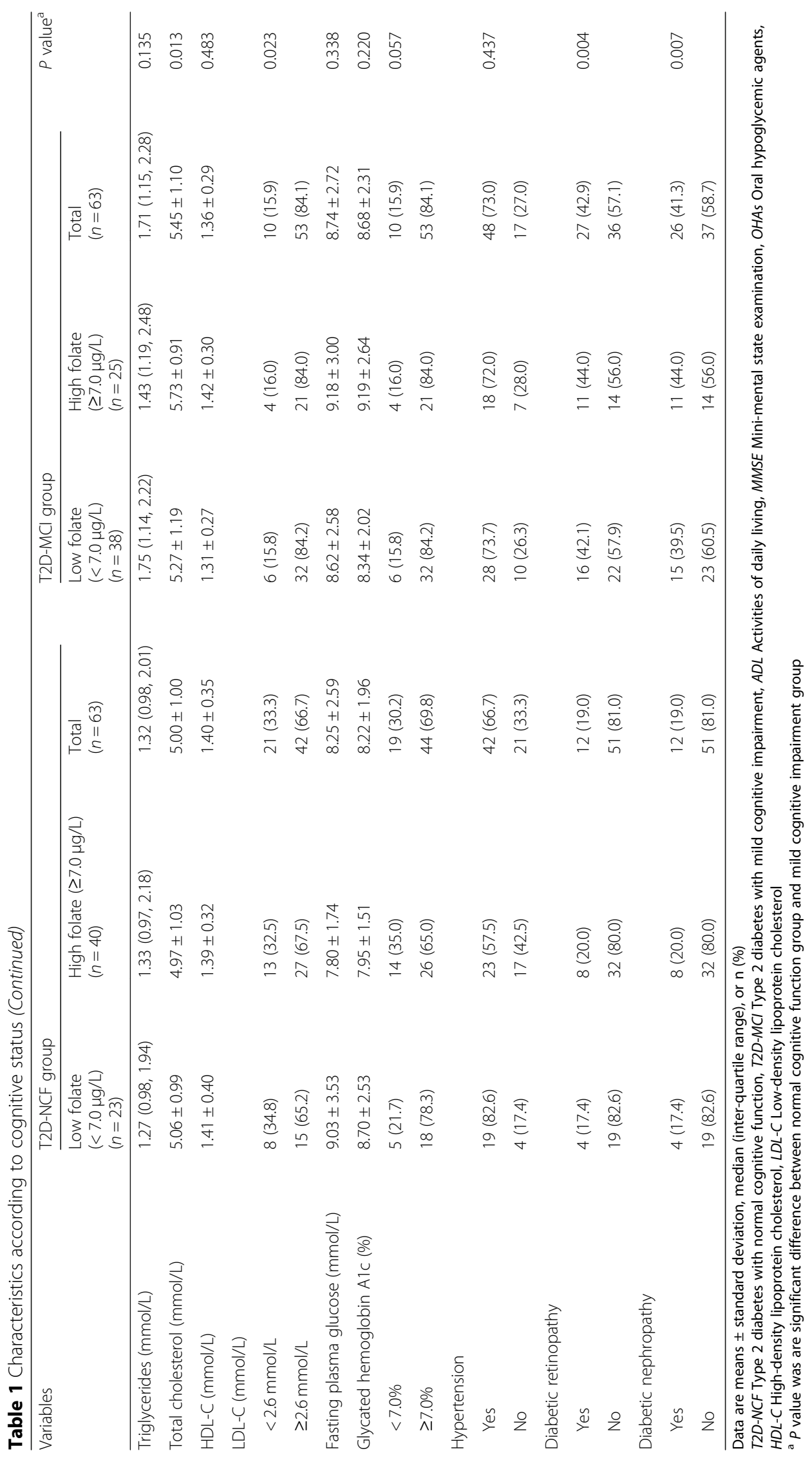


Table 2 Comparisions of serum folate and IL-6, TNF-a, hs-CRP according to cognitive status

\begin{tabular}{llll}
\hline Variables & T2D-NCF group $(n=63)$ & T2D-MCl group $(n=63)$ & $P$ value \\
\hline Folate $(\mu \mathrm{g} / \mathrm{L})$ & $8.07(6.65,10.40)$ & $6.25(5.30,7.94)$ & $<0.001$ \\
TNF-a $(\mathrm{pg} / \mathrm{ml})$ & $28.95(22.94,34.26)$ & $32.02(26.32,38.47)$ & 0.013 \\
IL-6(pg/ml) & $16.94(14.79,22.75)$ & $25.62(20.80,28.71)$ & $<0.001$ \\
hs-CRP $(\mathrm{mg} / \mathrm{L})$ & $0.80(0.50,1.50)$ & $1.40(0.80,3.10)$ & $<0.001$ \\
\hline
\end{tabular}

Values represent the median with inter-quartile range

T2D-NCF Type 2 diabetes with normal cognitive function, T2D-MCI Type 2 diabetes with mild cognitive impairment, IL-6 Interleukin-6, TNF- $a$ Tumor necrosis factora, $h s-C R P$ High-sensitivity C-reactive protein

have reported that the TNF-a, but not IL-6 level was significantly higher in cerebrospinal fluid of AD patients [32]. In contrast, Schuitemaker et al. [33] have reported that serum IL-6 level was significantly higher in MCI, which suggested that inflammatory processes might be involved in early stages of $\mathrm{AD}$, and different inflammatory markers might play major roles in certain developing stages of cognition decline. Moreover, Takeda et al. have found that IL6 and TNF- $\alpha$ were significantly higher in the brain microvessels of a new mice model that reflects the pathological conditions of both $\mathrm{AD}$ and diabetes compared with other genotypes which only reflects unique pathological characteristics of $\mathrm{AD}$ or diabetes. This indicated diabetic condition might enhance cognitive dysfunction by aggravating inflammation [5]. Our findings were similar to a crosssectional study from Scotland [12], which has shown that IL-6 was associated with estimated lifetime cognitive status after adjusting for vocabulary, education level, cardiovascular dysfunction, duration of diabetes, and glycemic control in older patients with T2D. The findings of a recent study from China have also suggested that plasma hs-CRP was associated with the risk of $\mathrm{MCI}$ among T2D patients [11]. Meanwhile, another Chinese case-control study in T2D has reported that the patients with MCI have a significantly higher hs-CRP than those without MCI, but CRP was not significantly correlated with the cognitive status [34]. Since aging was associated with chronic low-grade increases in circulating levels of inflammatory markers [24], the results differed from ours might due to the younger subjects (aged $63.45 \pm 8.38$ years) than ours (74.37 \pm 4.35 years). Recently, a meta-analysis has found that IL-6 level was inversely correlated with mean MMSE scores among numerous of peripheral inflammatory markers in patients with $\mathrm{AD}$ [7]. Plasma IL-6 level was inversely with hippocampal grey

Table 3 The correlations between serum folate and inflammatory markers

\begin{tabular}{lll}
\hline Inflammatory & Folate $(\mu \mathrm{g} / \mathrm{L})$ & \\
\cline { 2 - 3 } markers & $r$ value & $P$ value \\
\hline TNF-a $(\mathrm{pg} / \mathrm{ml})$ & -0.19 & 0.031 \\
IL-6 $(\mathrm{pg} / \mathrm{ml})$ & -0.21 & 0.019 \\
hs-CRP $(\mathrm{mg} / \mathrm{L})$ & -0.33 & $<0.001$ \\
\hline
\end{tabular}

TNF- $a$ Tumor necrosis factor-a, IL-6 Interleukin-6, hs-CRP High-sensitivity C-reactive protein matter volume, which was a structure critical for memory formation and associated with cognition decline [35]. Our findings were consistent with the above studies, which suggested that the inflammatory cytokine, IL-6 and hs-CRP might be a meaningful biological marker to link the cognitive impairment in T2D patients.

Our findings was consistent with the observation that inverse associations between serum hs-CRP and folate concentration existed in pregnant women [9]. A recent cross-sectional study of adolescents in Sweden has demonstrated that serum hs-CRP was significantly inversely associated with folate intakes [36]. As we known, hs-CRP is a reactant involved in the acute-phase response and rapidly increases in the presence of infection or inflammation, which is stimulated by the release of proinflammatory cytokines, including IL-1, IL- 6 and TNF- $\alpha$. Our study has suggested that folate might help control the acute-phase reactions of inflammation in T2D patients with $\mathrm{MCI}$.

We further included serum folate in the model to assess whether the associations between inflammation markers and MCI were mediated by serum folate level. Considering the MCI could be directly linked to the inflammation markers or the serum folate might have an indirect effect on MCI through improving the inflammation markers, we evaluated the associations of inflammation markers and $\mathrm{MCI}$ after further adjusting for serum folate. In the present study, there was a significant positive association of serum hs-CRP and MCI after adjusted for common diabetes related factors and cardiovascular diseases risk factors among T2D patients in the low folate subgroup $(<7.0 \mu \mathrm{g} / \mathrm{L})$. Our results have indicated that there might be somewhat relationship among peripheral folate, inflammatory cytokines and cognition status [37]. It has been reported that folate deficiency might enhance the expression of the inflammatory mediators including IL- $1 \beta$, IL- 6 and TNF- $\alpha$, independent of the concentration of homocysteine [38]. On the contrary, folic acid may inhibit lipopolysaccharide-induced production of IL- $1 \beta$ and TNF- $\alpha$ through inhibiting the MAPKs and NF- $\mathrm{KB}$ pathways [39]. A recent animal study aimed to evaluate the efficacy of folic acid in prevention of apoptosis by inhibiting TNF- $\alpha$ action in ischemia-reperfusion induced liver injury has also shown that folic acid might inhibit apoptosis by inhibiting the 
Table 4 Odds ratios of $\mathrm{MCl}$ for inflammatory markers

\begin{tabular}{|c|c|c|c|c|c|c|c|c|}
\hline \multirow[t]{2}{*}{ Variables } & \multirow[t]{2}{*}{ Tertile } & \multirow{2}{*}{$\begin{array}{l}\text { Controls/ } \\
\text { Case }\end{array}$} & \multicolumn{2}{|l|}{ Model 1} & \multicolumn{2}{|l|}{ Model 2} & \multicolumn{2}{|l|}{ Model 3} \\
\hline & & & $\mathrm{OR}(95 \% \mathrm{Cl})$ & $P$ value & $\mathrm{OR}(95 \% \mathrm{Cl})$ & $P$ value & $\mathrm{OR}(95 \% \mathrm{Cl})$ & $P$ value \\
\hline \multirow[t]{3}{*}{ TNF-a } & $<26.33 \mathrm{pg} / \mathrm{ml}$ & $26 / 16$ & 1.00 & - & 1.00 & - & 1.00 & - \\
\hline & $26.33-33.83 \mathrm{pg} / \mathrm{ml}$ & $20 / 22$ & $1.38(0.73-2.62)$ & 0.332 & $1.46(0.75-2.83)$ & 0.133 & $1.48(0.76-2.89)$ & 0.250 \\
\hline & $\geq 33.83 \mathrm{pg} / \mathrm{ml}$ & $17 / 25$ & $1.56(0.83-2.93)$ & 0.163 & $1.47(0.77-2.80)$ & 0.238 & $1.41(0.74-2.69)$ & 0.296 \\
\hline \multirow[t]{3}{*}{ IL-6 } & $<16.91 \mathrm{pg} / \mathrm{ml}$ & $31 / 11$ & 1.00 & - & 1.00 & - & 1.00 & - \\
\hline & $16.91-25.35 \mathrm{pg} / \mathrm{ml}$ & $24 / 18$ & $1.64(0.77-3.47)$ & 0.198 & $1.90(0.88-4.12)$ & 0.105 & $1.96(0.90-4.26)$ & 0.091 \\
\hline & $\geq 25.35 \mathrm{pg} / \mathrm{ml}$ & $8 / 34$ & $3.09(1.57-6.10)$ & 0.001 & $3.15(1.58-6.28)$ & 0.001 & $3.12(1.56-6.24)$ & 0.001 \\
\hline \multirow[t]{3}{*}{ hs-CRP } & $<0.63 \mathrm{mg} / \mathrm{L}$ & $30 / 12$ & 1.00 & - & 1.00 & - & 1.00 & - \\
\hline & $0.63-1.67 \mathrm{mg} / \mathrm{L}$ & $18 / 24$ & $2.00(1.00-4.00)$ & 0.050 & $1.87(0.92-3.79)$ & 0.083 & $1.79(0.88-3.66)$ & 0.108 \\
\hline & $\geq 1.67 \mathrm{mg} / \mathrm{L}$ & $15 / 27$ & $2.25(1.14-4.44)$ & 0.019 & $2.14(1.05-4.35)$ & 0.035 & $2.02(0.98-4.14)$ & 0.055 \\
\hline
\end{tabular}

Model 1: Crude model

Model 2: Adjusted for diabetes related factors including duration of diabetes (per year), HbA1c $(<7.0 \% / \geq 7.0 \%)$, anti-diabetic medications (only oral hypoglycemic agents /only insulin/insulin plus oral hypoglycemic agents), diabetic retinopathy (yes/no) and diabetic nephropathy (yes/no), and common cardiovascular diseases risk factors including smoking status (yes/no), body mass index $\left(<24.0 \mathrm{~kg} / \mathrm{m}^{2} / 24.0-28.0 \mathrm{~kg} / \mathrm{m}^{2} / \geq 28.0 \mathrm{~kg} / \mathrm{m}^{2}\right)$, hypertension (yes $/ \mathrm{no}$ ),

$\mathrm{LDL}-\mathrm{C}(<2.6 \mathrm{mmol} / \mathrm{L} / \geq 2.6 \mathrm{mmol} / \mathrm{L})$

Model 3: Model 2 plus serum folate $(<7.0 \mu \mathrm{g} / \mathrm{L} / \geq 7.0 \mu \mathrm{g} / \mathrm{L})$

IL-6 Interleukin-6, TNF-a Tumor necrosis factor-a, $h s-C R P$ High-sensitivity C-reactive protein

action of TNF- $\alpha$ [40]. Moreover, folic acid supplement to the patients with MCI could significantly reduce peripheral TNF- $\alpha$ and IL-6 levels [41]. These data indicated that optimal serum folate status might influence the release of proinflammatory cytokines such as IL- 6 and TNF- $\alpha$ among T2D patients with MCI. Thus, more randomized controlled trials will be performed to explore whether serum folate might have an indirect effect on MCI through improving the inflammation reactions among T2D patients.

The previous studies have demonstrated that low folate and elevated homocysteine levels were associated with $\mathrm{MCI}$ in older population [42]. Low folate status, which is a well-known strong determinant of homocysteine levels, could lead to elevated homocysteine, which in turn lead to cognitive impairment [43]. Moreover, other nutrients other than folate or dietary pattern may be exert greater effects on inflammatory processes and neurodegeneration. For instance, the Mediterranean diet (MD) rich in polyunsaturated fatty acids, trace elements and vitamins, has shown promising associations with slower rate of cognitive decline [44] due to its proven anti-inflammatory [45]. Thus, the serum homocysteine and other nutrients such as vitamin $C$, vitamin $E$, vitamin $B_{12}$ and vitamin $D$ will be measured to explore the effects of other related nutrients on the relationship between inflammatory markers and $\mathrm{MCI}$ in T2D patients in future study. On the other hand, the relationship between inflammation and MCI did not exist among the subjects with high folate $(\geq 7.0 \mu \mathrm{g} / \mathrm{L})$ in our study, which indicated that there might be some other main factors to link inflammation and MCI. In our study, the patients with mild microvascular complications such as persistent microalbuminuria, non-proliferative diabetic retinopathy were enrolled. And the percentage of diabetic retinopathy $(42.9 \%)$ and diabetic nephropathy $(41.3 \%)$ in the case group was significantly higher than that in the control group (19.0 and 19.0\%, respectively). The persistent albuminuria or diabetic retinopathy was associated with a decline in cognitive function with diabetes [46, 47]. And both diabetic nephropathy and retinopathy were vascular risk factors. One possible mechanism of MCI related to diabetic microvascular complication was that the decrease of nitric oxide in the patients with diabetic retinopathy and diabetic nephropathy $[48,49]$, which could lead to vascular impairment due to endothelial cell injury. In addition, the plasma levels of inflammatory biomarkers were associated with the incidence and development of diabetic vascular

Table 5 Odds ratios of $\mathrm{MCl}$ for inflammatory markers stratified by serum folate ${ }^{\text {a }}$

\begin{tabular}{|c|c|c|c|c|c|c|c|}
\hline \multirow[t]{2}{*}{ Variable } & \multirow[t]{2}{*}{ Tertile } & \multicolumn{3}{|c|}{$\begin{array}{l}\text { Low folate subgroup }(<7.0 \mu \mathrm{g} / \mathrm{L}) \\
(n=61)\end{array}$} & \multicolumn{3}{|c|}{$\begin{array}{l}\text { High folate subgroup }(\geq 7.0 \mu \mathrm{g} / \mathrm{L}) \\
(n=65)\end{array}$} \\
\hline & & Controls/ Case & OR(95\%Cl) & $P$ value & Controls / Case & OR(95\%Cl) & $P$ value \\
\hline \multirow[t]{3}{*}{ hs-CRP } & $<0.63 \mathrm{mg} / \mathrm{L}$ & $12 / 4$ & 1.00 & - & $18 / 8$ & 1.00 & - \\
\hline & $0.63-1.67 \mathrm{mg} / \mathrm{L}$ & $6 / 15$ & $2.95(0.90-9.63)$ & 0.074 & $12 / 9$ & $2.04(0.68-6.17)$ & 0.205 \\
\hline & $\geq 1.67 \mathrm{mg} / \mathrm{L}$ & $5 / 19$ & $3.34(1.05-10.64)$ & 0.042 & $10 / 8$ & $2.16(0.68-6.88)$ & 0.194 \\
\hline
\end{tabular}

${ }^{a}$ Adjusted for diabetes related factors including duration of diabetes (per year), HbA1c $(<7.0 \% / \geq 7.0 \%)$, anti-diabetic medications (only oral hypoglycemic agents /only insulin/insulin plus oral hypoglycemic agents), diabetic retinopathy (yes/no) and diabetic nephropathy (yes/no), and common cardiovascular diseases risk factors including smoking status (yes $/ \mathrm{no}$ ), body mass index $\left(<24.0 \mathrm{~kg} / \mathrm{m}^{2} / 24.0-28.0 \mathrm{~kg} / \mathrm{m}^{2} / \geq 28.0 \mathrm{~kg} / \mathrm{m}^{2}\right.$ ), hypertension (yes/no), LDL-C $(<2.6 \mathrm{mmol} / \mathrm{L} / \geq 2.6 \mathrm{mmol} / \mathrm{L})$ 
complication in type 1 and type 2 diabetes [50]. Thus, the vascular factors might be considered as a main factor that links inflammation and $\mathrm{MCI}$ in the high folate subgroup.

The following limitations of the current study should be considered. First, case-control design, temporality is not clear; further longitudinal studies and randomized controlled trials are needed to examine the temporal sequence of this association. Second, the results of this case-control study may be misinterpreted because of the influence of farraginous factors, random and systematic recall errors, and selection bias. Third, the small sample size and single ethnicity of the surveyed subjects may limit the application of our results to other ethnic groups. Finally, the conclusion of this study should be interpreted carefully as T2DM itself may increase the risk of MCI via different mechanisms.

\section{Conclusions}

Serum IL-6 and hs-CRP were associated with the risk of $\mathrm{MCI}$ among Chinese patients with T2D. Moreover, serum hs-CRP was associated with MCI only among T2D patients with low serum folate level $(<7.0 \mu \mathrm{g} / \mathrm{L})$, but not among those whose serum folate level was higher than $7.0 \mu \mathrm{g} / \mathrm{L}$. It suggested that serum folate levels might modify the association between serum hs-CRP and MCI.

\begin{abstract}
Abbreviations
AD: Alzheimer disease; ADL: Activities of daily living; BMl: Body mass index; Cl: Confidence intervals; DBP: Diastolic blood pressure; eGFR: Estimated glomerular filtration rate; FPG: Fasting plasma glucose; GHbA1c: Glycated hemoglobin A1c; HDL-C: High-density lipoprotein cholesterol; hs-CRP: Highsensitivity C-reactive protein; IL-6: Interleukin-6; LDL-C: Low-density lipoprotein cholesterol; MCl: Mild cognitive impairment; MMSE: Mini-Mental State Examination; NCF: Normal cognitive function; OHAs: Oral hypoglycemic agents; OR: Odds ratio; SBP: Systolic blood pressure; T2D: Type 2 diabetes; T2D-MCl: Type 2 diabetes with mild cognitive impairment; T2D-NCF: Type 2 diabetes with normal cognitive function; TC: Total cholesterol;

TG: Triglycerides; TNF-a: Tumor necrosis factor-a
\end{abstract}

\section{Acknowledgements}

We thank all the participants and staff of the Tianjin Medical University Metabolic Diseases Hospital for their contribution to this study.

\section{Authors' contributions}

MZhe and MZha designed the study and draft the manuscript. BC and GH conceived and reviewed the manuscript. LT and CS participated in the study design and data collection. HC and YG performed the statistical analysis. All authors read and approved the final manuscript.

\section{Funding}

This study was supported by the Key Program of National Natural Science Foundation of China [grant numbers: 81730091]; and National Natural Science Foundation of China [grant number: 81502809]. The funding bodies had no role in the design of the study and collection, analysis, and interpretation of data and in writing the manuscript.

\section{Availability of data and materials}

The data that support the findings of this study are available on request from the corresponding author on reasonable request.

\section{Ethics approval and consent to participate}

The study protocol was approved by the Ethics Committee of Tianjin Medical University. All participants provided written informed consent before participating in the study.

Consent for publication

Not applicable.

\section{Competing interests}

The authors declare that they have no competing interests.

\section{Author details}

${ }^{1} \mathrm{NHC}$ Key Laboratory of Hormones and Development, Tianjin Key Laboratory of Metabolic Diseases, Metabolic Diseases Hospital \& Institute of Endocrinology, Tianjin Medical University, Tianjin, China. ${ }^{2}$ Department of Clinical Laboratory, Tianjin Chest Hospital, Tianjin, China. ${ }^{3}$ School of Nursing, Tianjin Medical University, Tianjin, China. ${ }^{4}$ Department of Cardiology, Tianjin Medical University General Hospital, Tianjin, China. ${ }^{5}$ Department of Nutrition and Food Science, School of Public Health, Tianjin Medical University, Tianjin, China. ${ }^{6}$ Tianjin Key Laboratory of Environment, Nutrition and Public Health,

Tianjin, China. ${ }^{7}$ Center for International Collaborative Research on

Environment, Nutrition and Public Health, Tianjin, China.

Received: 10 January 2019 Accepted: 25 June 2019

Published online: 11 July 2019

\section{References}

1. Levey A, Lah J, Goldstein F, Steenland K, Bliwise D. Mild cognitive impairment: an opportunity to identify patients at high risk for progression to Alzheimer's disease. Clin Ther. 2006:28:991-1001.

2. Petersen RC. Mild cognitive impairment as a diagnostic entity. J Intern Med. 2004;256:183-94.

3. Profenno LA, Porsteinsson AP, Faraone SV. Meta-analysis of Alzheimer's disease risk with obesity, diabetes, and related disorders. Biol Psychiatry. 2010;67:505-12

4. Dybjer E, Nilsson PM, Engström G, Helmer C, Nägga K. Pre-diabetes and diabetes are independently associated with adverse cognitive test results: a cross-sectional, population-based study. BMC Endocr Disord. 2018;18:91.

5. Takeda S, Sato N, Uchio-Yamada K, Sawada K, Kunieda T, Takeuchi D, et al. Diabetes-accelerated memory dysfunction via cerebrovascular inflammation and Abeta deposition in an Alzheimer mouse model with diabetes. Proc Natl Acad Sci U S A. 2010;107:7036-41.

6. Zhao SJ, Guo CN, Wang MQ, Chen WJ, Zhao YB. Serum levels of inflammation factors and cognitive performance in amnestic mild cognitive impairment: a Chinese clinical study. Cytokine. 2012;57:221-5.

7. KSP L, Liu CS, Rau A, Lanctôt KL, Köhler CA, Pakosh M, et al. Peripheral inflammatory markers in Alzheimer's disease: a systematic review and metaanalysis of 175 studies. J Neurol Neurosurg Psychiatry. 2017:88:876-82.

8. Araújo JR, Martel F, Borges N, Araújo JM, Keating E. Folates and aging: role in mild cognitive impairment, dementia and depression. Ageing Res Rev. 2015;22:9-19.

9. Kim H, Hwang JY, Ha EH, Park H, Ha M, Lee SJ, et al. Association of maternal folate nutrition and serum C-reactive protein concentrations with gestational age at delivery. Eur J Clin Nutr. 2011;65:350-6.

10. Xu G, Zhou Z, Zhu W, Fan X, Liu X. Plasma C-reactive protein is related to cognitive deterioration and dementia in patients with mild cognitive impairment. J Neurol Sci. 2009;284:77-80.

11. Cai R, Huang R, Han J, Sun H, Sun J, Xia W, et al. Lipoprotein-associated phospholipase A2 is associated with risk of mild cognitive impairment in Chinese patients with type 2 diabetes. Sci Rep. 2017;7:12311.

12. Marioni RE, Strachan MW, Reynolds RM, Lowe GD, Mitchell RJ, Fowkes FG, et al. Association between raised inflammatory markers and cognitive decline in elderly people with type 2 diabetes: the Edinburgh type 2 diabetes study. Diabetes. 2010:59:710-3.

13. Ma F, Li Q, Zhou X, Zhao J, Song A, Li W, et al. Effects of folic acid supplementation on cognitive function and $A \beta$-related biomarkers in mild cognitive impairment: a randomized controlled trail. Eur J Nutr. 2019;58:345-56.

14. International Diabetes Federation Guideline Development Group. Global guideline for type 2 diabetes. Diabetes Res Clin Pract. 2014;104:1-52.

15. Stevens PE, Levin A, Kidney Disease: Improving Global Outcomes Chronic Kidney Disease Guideline Development Work Group Members. Evaluation and management of chronic kidney disease: synopsis of the kidney disease: 
improving global outcomes 2012 clinical practice guideline. Ann Intern Med. 2013;158:825-30.

16. Levey AS, Stevens LA, Schmid CH, Zhang YL, Castro AF 3rd, Feldman HI, et al. A new equation to estimate glomerular filtration rate. Ann Intern Med. 2009;150:604-12

17. Iqbal A, Heller S. Managing hypoglycaemia. Best Pract Res Clin Endocrinol Metab. 2016;30:413-30

18. Folstein MF, Folstein SE, McHugh PR. "Mini-mental state". A practical method for grading the cognitive state of patients for the clinician. J Psychiatr Res. 1975;12:189-98.

19. Lee J, Lam L, Woo J, Kwok T. Lower fluid and fruits/vegetable intake in questionable dementia among older Hong Kong Chinese. J Nutr Health Aging. 2010;14:45-9.

20. Wang $H$, Chen $K$, Pan $Y$, Jing F, Liu H. Associations and impact factors between living arrangements and functional disability among older Chinese adults. PLoS One. 2013;8:e53879.

21. Petersen RC, Doody R, Kurz A, Mohs RC, Morris JC, Rabins PV, et al. Current concepts in mild cognitive impairment. Arch Neurol. 2001;58:1985-92.

22. Pichot P. DSM-III: the $3 \mathrm{~d}$ edition of the diagnostic and statistical manual of mental disorders from the American Psychiatric Association. Rev Neurol (Paris). 1986;142:489-99.

23. Daly LE, Kirke PN, Molloy A, Weir DG, Scott JM. Folate levels and neural tube defects. Implications for prevention. JAMA. 1995;274:1698-702.

24. Brüünsgaard $H$, Pedersen BK. Age-related inflammatory cytokines and disease. Immunol Allergy Clin N Am. 2003;23:15-39.

25. Mengel E, Tillmann V, Remmel L, Kool P, Purge P, Lätt E, et al. Changes in inflammatory markers in estonian pubertal boys with different BMI values and increments: a 3-year follow-up study. Obesity (Silver Spring). 2017;25:600-7.

26. McEvoy JW, Nasir K, DeFilippis AP, Lima JA, Bluemke DA, Hundley WG, et al. Relationship of cigarette smoking with inflammation and subclinical vascular disease: the multi-ethnic study of atherosclerosis. Arterioscler Thromb Vasc Biol. 2015:35:1002-10.

27. Hsu SH, Jang MH, Torng PL, Su TC. Positive association between small dense low-density lipoprotein cholesterol concentration and biomarkers of inflammation, thrombosis, and prediabetes in non-diabetic adults. J Atheroscler Thromb. 2018. https://doi.org/10.5551/jat.43968.

28. Sheen YJ, Sheu WH. Association between hypoglycemia and dementia in patients with type 2 diabetes. Diabetes Res Clin Pract. 2016;116:279-87.

29. Schram MT, Euser SM, de Craen AJ, Witteman JC, Frölich M, Hofman A, et al. Systemic markers of inflammation and cognitive decline in old age. J Am Geriatr Soc. 2007;55:708-16.

30. Athilingam P, Moynihan J, Chen L, D'Aoust R, Groer M, Kip K. Elevated levels of interleukin 6 and C-reactive protein associated with cognitive impairment in heart failure. Congest Heart Fail. 2013;19:92-8.

31. Zuliani G, Ranzini M, Guerra G, Rossi L, Munari MR, Zurlo A, et al. Plasma cytokines profile in older subjects with late onset Alzheimer's disease or vascular dementia. J Psychiatr Res. 2007:41:686-93.

32. Tarkowski E, Liljeroth AM, Minthon L, Tarkowski A, Wallin A, Blennow K. Cerebral pattern of pro- and anti-inflammatory cytokines in dementias. Brain Res Bull. 2003;61:255-60.

33. Schuitemaker A, Dik MG, Veerhuis R, Scheltens $P$, Schoonenboom NS, Hack $\mathrm{CE}$, et al. Inflammatory markers in $\mathrm{AD}$ and $\mathrm{MCl}$ patients with different biomarker profiles. Neurobiol Aging. 2009;30:1885-9.

34. Chen G, Cai L, Chen B, Liang J, Lin F, Li L, et al. Serum level of endogenous secretory receptor for advanced glycation end products and other factors in type 2 diabetic patients with mild cognitive impairment. Diabetes Care. 2011;34:2586-90.

35. Marsland AL, Gianaros PJ, Abramowitch SM, Manuck SB, Hariri AR. Interleukin-6 covaries inversely with hippocampal grey matter volume in middle-aged adults. Biol Psychiatry. 2008;64:484-90.

36. Holt EM, Steffen LM, Moran A, Basu S, Steinberger J, Ross JA, et al. Fruit and vegetable consumption and its relation to markers of inflammation and oxidative stress in adolescents. J Am Diet Assoc. 2009;109:414-21.

37. Handing EP, Small BJ, Andel R, McEvoy CL, Kumar N. Can nutrition or inflammation moderate the age-cognition association among older adults. J Gerontol B Psychol Sci Soc Sci. 2019;74:193-201.

38. Kolb AF, Petrie L. Folate deficiency enhances the inflammatory response of macrophages. Mol Immunol. 2013;54:164-72.

39. Feng D, Zhou Y, Xia M, Ma J. Folic acid inhibits lipopolysaccharide-induced inflammatory response in RAW264.7 macrophages by suppressing MAPKs and NF-KB activation. Inflamm Res. 2011;60:817-22.
40. Chattopadhyay P, Wahi AK. Inhibition by folic acid of tumor necrosis factor alpha and apoptosis following normothermic ischemia-reperfusion. Arzneimittelforschung. 2010;60:621-6.

41. Ma F, Wu T, Zhao J, Song A, Liu H, Xu W, et al. Folic acid supplementation improves cognitive function by reducing the levels of peripheral inflammatory cytokines in elderly Chinese subjects with MCl. Sci Rep. 2016;6:37486.

42. Ma F, Wu T, Zhao J, Ji L, Song A, Zhang M, et al. Plasma homocysteine and serum folate and vitamin B12 levels in mild cognitive impairment and Alzheimer's disease: a case-control study. Nutrients. 2017;9. https://doi.org/ 10.3390/nu9070725.

43. Smith AD, Refsum H. Homocysteine, B vitamins, and cognitive impairment. Annu Rev Nutr. 2016;36:211-39.

44. Tangney CC, Li H, Wang Y, Barnes L, Schneider JA, Bennett DA, et al. Relation of DASH- and Mediterranean-like dietary patterns to cognitive decline in older persons. Neurology. 2014;83:1410-6.

45. Casas R, Urpi-Sardà M, Sacanella E, Arranz S, Corella D, Castañer O, et al. Antiinflammatory effects of the Mediterranean diet in the early and late stages of atheroma plaque development. Mediat Inflamm. 2017;2017:3674390.

46. Barzilay JI, Lovato JF, Murray AM, Williamson J, Ismail-Beigi F, Karl D, et al. Albuminuria and cognitive decline in people with diabetes and normal renal function. Clin J Am Soc Nephrol. 2013;8:1907-14.

47. Hugenschmidt CE, Lovato JF, Ambrosius WT, Bryan RN, Gerstein HC, Horowitz KR et al. The cross-sectional and longitudinal associations of diabetic retinopathy with cognitive function and brain MRI findings: the action to control cardiovascular risk in diabetes (ACCORD) trial. Diabetes Care. 2014;37:3244-52.

48. Opatrilova R, Kubatka P, Caprnda M, Büsselberg D, Krasnik V, Vesely P, et al. Nitric oxide in the pathophysiology of retinopathy: evidences from preclinical and clinical researches. Acta Ophthalmol. 2018;96:222-31.

49. Tessari P. Nitric oxide in the normal kidney and in patients with diabetic nephropathy. J Nephrol. 2015;28:257-68.

50. Domingueti CP, Dusse LM, Md C, de Sousa LP, Gomes KB, Fernandes AP. Diabetes mellitus: the linkage between oxidative stress, inflammation, hypercoagulability and vascular complications. J Diabetes Complicat. 2016; 30:738-45.

\section{Publisher's Note}

Springer Nature remains neutral with regard to jurisdictional claims in published maps and institutional affiliations.

\section{Ready to submit your research? Choose BMC and benefit from:}

- fast, convenient online submission

- thorough peer review by experienced researchers in your field

- rapid publication on acceptance

- support for research data, including large and complex data types

- gold Open Access which fosters wider collaboration and increased citations

- maximum visibility for your research: over $100 \mathrm{M}$ website views per year

At $\mathrm{BMC}$, research is always in progress.

Learn more biomedcentral.com/submissions 